\title{
Pediatric Orthopaedics - from Kirschner wires to titanium
}

\author{
Patricia M. M. B. Fucs ${ }^{1}$ - Marius M. Scarlat ${ }^{2}$
}

Published online: 27 October 2017

(C) SICOT aisbl 2017

The world of Pediatric Orthopaedics is facing perpetual and recurrent challenges and modern science brings more requests for quality and results. The Hippocratic quote 'The life so short, the craft so long to learn" is so true especially for Pediatric Orthopaedics. The formidable challenges of genetics and histology related to growth are so important in the biology of infants and the lessons we learn with each new case, research, study are making this specialty particularly dynamic.

At origins of our art, the so-called Orthopedic Physician was the Pediatric Specialist, since the meaning of the word "orthopedic" comes from the Greek words ORTHOS (STRAIGHT) and PEDOS (CHILD). It is normal that "International Orthopaedics" holds and cultivates a strong and visible pediatric section as our colleagues doing "General Orthopaedics" face pediatric cases in a vast majority of centers allover the globe.

The lessons learned by the first Author in the past twenty years as Pediatric Orthopaedic Specialist were so many... Some easily learned and some with difficulty. A couple of decades ago we started the study of orthopedics and integrated meanwhile children development, pediatric neurology, biomechanics, physiotherapy occupational therapy and so many related neighboring specialties. The learning of best conservative treatments was tedious. Coping with different conditions

Marius M. Scarlat

mscarlat@gmail.com

Patricia M. M. B. Fucs

pmmbf@icloud.com

1 Orthopaedic Department - Santa Casa de São Paulo, Faculdade de Ciências Médicas da Santa Casa de Sāo Paulo, R Dr Cesário Motta Jr, 112, Sāo Paulo 01221-020, Brazil

2 Clinique St Michel, Toulon, France in patients and families was - and remains - depending on our ability as physicians to communicate. We learned that understanding what is happening is key for our little patients and they can participate in the healing process to make it better, faster and less scary. We learned that casting techniques could be different from the textbooks when you have the crying child in front of you, and you have to think where is the fracture, how is the displacement and what is the best fixation for stabilization, how to carefully manage the points of support of the cast and how to make the cast more suitable and fun for the child. This represents a long learning curve for all of us.

Nowadays treatments are changing and becoming more interventional, many of the fractures treated in the past with traction and cast are now being operated to avoid long hospital stay in order to recover the patient as fast as possible. New techniques are always arriving.

The implants made a sensational progress - from the good old stainless steel Kirschner wires that were supposed to fix everything - to modern plates, low-contact plates, titanium implants for limbs and spine and overall a whole new era of industrial modern products.

Genetics today, with all the technology, continue to help us to better understand the diseases, to delineate a prognosis and to give counseling to the families with a more accurate pattern. We encourage publications describing genetic conditions as diagnosis is important for all of us and reliable treatment is often based on early diagnosis (1). Prevision changed from defining fate to choices for therapeutic options as today genetic interventions could change life and dramatically improve outcomes. Bone substitutes currently used today (2) will probably make place to genetically controlled bone and tissue growth and so will probably progress the cartilage transplant (3-5).

For patients with Cerebral Palsy (CP) many new and topics arrived to be learned, the study of the gait analysis changed enormously our way of seeing and treating the patients. We 
learned biomechanics, understood forces, interfered with muscle command and power, we treated lever-arm diseases... as we were growing we had lots of new information to integrate.

Surgical options offered to our patients with $\mathrm{CP}$ better quality of life as the new implants were more stable, the casting was not necessary anymore and the possibility to make multiple procedures in one setting arrived and the care for the $\mathrm{CP}$ improved greatly (6). From the old 90 degree plate for hip osteotomies to the new LCP angular plate - what an improvement! One always need to remember, especially in the neuromuscular patient that: "The decisions are more important than the incisions", as Dr Robert Salter once said. The need to respect the principles and the priorities in the treatment is of course basic. Genetic diseases such as hemophilia are being managed with conventional surgery in youngsters (7) while the scientific community is looking forward to some creative mutation that would fix everything before complications occur.

Ponseti's technique also changed completely the way of treating clubfoot, we had to go back to our way of doing it and learn the new technique. Evaluation and follow-up are essential for the success in this delicate and more biologic, less aggressive approach. It took time to understand and improve our skills, change attitude and management, another learning curve ahead. The biology and growth of the normal foot were one important lesson to learn (8). On the other side, less surgery now is needed but if necessary, less training is now on. So in the future, only a small group of surgeons will be able to deal with the more complex cases. Another issue to be addressed soon.

The world of Pediatric Orthopaedics is a particular place with different patients, different methods and different tools as compared to the regular adults Services. The dedicated Pediatric Journals are receiving and publishing more and more information and progress is seen in volume and quality of research. Our Pediatric Section publishes papers in each issue of "International Orthopaedics". Some of those papers become highly cited and respected. We should acknowledge as usual the reviewers of the Pediatric Section who help us with decision-making and point out qualities and weaknesses in each submitted paper.

Developmental medicine includes the study of hip dysplasia and related prevention and complications and this is still a topic of debate bringing valuable contributions to the Journal (9). Treatment includes different techniques and the evaluation of outcomes in long-term follow-up is always welcome in our Journal (10). Hematogenous osteomyelitis is still hurting and making victims allover the world, we published recently an educational and significant paper with information about the scientific management of this condition (11).

The majority of our pediatric papers are describing treatments and options with trauma. Children traumatology is a major concern for the Pediatric Services and also for General Orthopaedic surgeons who receive trauma worldwide.
Therefore the number of papers dedicated to upper limb (12-15) and lower limb (16-18) is completed with publications about spine and pelvic trauma $(19,20)$. Other fields of interest with substantial results are published in the study of the LeggCalvé-Perthes disease (21) and in the pediatric oncology (22)

Training to develop medical thinking and surgical skills is a complex journey. The techniques and procedures are integrated with experience and years of practice and the young surgeons need to consciously repeat and repeat procedures to reach excellence in practice. The other side of this learning process is to know how to indicate the surgery.

Ancient quotes are still valid today:

- The physician should not treat the disease but the patient who is suffering from it - Maimonides

- The physician must be able to tell the antecedents, know the present, and foretell the future - must mediate these things, and have two special objects in view with regard to disease, namely, to do good or to do no harm." Hippocrates

- The good physician treats the disease; the great physician treats the patient who has the disease. - William Osler

- Learning Orthopaedics is a hard work requiring long days and nights of study and learning the art of Pediatric Orthopaedics require specific commitments for a lifetime. - Patricia Fucs

\section{References}

1. Binh HD, Maasalu K, Dung VC, Ngoc CT, Hung TT, Nam TV, Nhan LN, Prans E, Reimann E, Zhytnik L, Kõks S, Märtson A (2017) The clinical features of osteogenesis imperfecta in Vietnam. Int Orthop 41(1):21-29. https://doi.org/10.1007/s00264016-3315-z

2. Pesenti S, Ghailane S, Varghese JJ, Ollivier M, Peltier E, Choufani E, Bollini G, Blondel B, Jouve JL (2017) Bone substitutes in adolescent idiopathic scoliosis surgery using sublaminar bands: is it useful? A case-control study. Int Orthop. https://doi.org/10.1007/ s00264-017-3512-4

3. Niethammer TR, Holzgruber M, Gülecyüz MF, Weber P, Pietschmann MF, Müller PE (2017) Matrix based autologous chondrocyte implantation in children and adolescents: a match paired analysis in a follow-up over three years post-operation. Int Orthop 41(2):343-350. https://doi.org/10.1007/s00264-016-3321-1

4. Chadli L, Cottalorda J, Delpont M, Mazeau P, Thouvenin Y, Louahem D (2017) Autologous osteochondral mosaicplasty in osteochondritis dissecans of the patella in adolescents. Int Orthop 41(1):197-202. https://doi.org/10.1007/s00264-016-3198-z

5. Agarwal A, Kumar A (2016) Fibula regeneration following nonvascularized graft harvest in children. Int Orthop 40(10):2191-2197

6. Yamada HH, Fucs PMMB (2017) Long-term results of fibularAchilles tenodesis (Westin's tenodesis) for paralytic pes calcaneus: is hypercorrection avoidable? A longitudinal retrospective study. Int Orthop 41(8):1641-1646. https://doi.org/10.1007/s00264-017-3458-6

7. de l'Escalopier N, Badina A, Padovani JP, Harroche A, Frenzel L, Wicart P, Glorion C, Rothschild C (2017) Long-term results of 
ankle arthrodesis in children and adolescents with haemophilia. Int Orthop 41(8):1579-1584. https://doi.org/10.1007/s00264-017$3478-2$

8. Gupta P, Mittal N, Jindal N, Verma P, Sharma M (2017) A study of normal foot abduction across various age groups in children. Int Orthop. https://doi.org/10.1007/s00264-017-3603-2

9. Kolb A, Schweiger N, Mailath-Pokorny M, Kaider A, Hobusch G, Chiari C, Windhager R (2016) Low incidence of early developmental dysplasia of the hip in universal ultrasonographic screening of newborns: analysis and evaluation of risk factors. Int Orthop 40(1): 123-127. https://doi.org/10.1007/s00264-015-2799-2

10. Holm AG, Reikerås $\mathrm{O}$, Terjesen $\mathrm{T}$ (2017) Long-term results of a modified Spitzy shelf operation for residual hip dysplasia and subluxation. A fifty year follow-up study of fifty six children and young adults. Int Orthop 41(2):415-421. https://doi.org/10.1007/ s00264-016-3286-0

11. Cohen E, Lifshitz K, Fruchtman Y, Eidelman M, Leibovitz E (2016) Current data on acute haematogenous osteomyelitis in children in Southern Israel: epidemiology, microbiology, clinics and therapeutic consequences. Int Orthop 40(9):1987-1994. https://doi.org/10. 1007/s00264-016-3211-6

12. Canavese F, Marengo L, Tiris A, Mansour M, Rousset M, Samba A, Andreacchio A, Dimeglio A (2017) Radiological, clinical and functional evaluation using the quick disabilities of the arm, shoulder and hand questionnaire of children with medial epicondyle fractures treated surgically. Int Orthop. https://doi.org/10.1007/s00264017-3442-1

13. Sofu H, Gursu S, Camurcu Y, Yildirim T, Sahin V (2016) Pure elbow dislocation in the paediatric age group. Int Orthop 40(3): 541-545. https://doi.org/10.1007/s00264-015-3074-2

14. Sinikumpu JJ, Pokka T, Victorzon S, Lindholm EL, Serlo W (2017) Paediatric lateral humeral condylar fracture outcomes at twelve years follow-up as compared with age and sex matched paired controls. Int Orthop. https://doi.org/10.1007/s00264017-3451-0
15. Farr S, Zechmann U, Ganger R, Girsch W (2015) Clinical experience with arthroscopically-assisted repair of peripheral triangular fibrocartilage complex tears in adolescents-technique and results. Int Orthop 39(8):1571-1577. https://doi.org/10.1007/s00264-0152795-6

16. Canavese F, Marengo L, Andreacchio A, Mansour M, Paonessa M, Rousset M, Samba A, Dimeglio A (2016) Complications of elastic stable intramedullary nailing of femoral shaft fractures in children weighing fifty kilograms (one hundred and ten pounds) and more. Int Orthop 40(12):2627-2634

17. Panigrahi R, Sahu B, Mahapatra AK, Palo N, Priyadarshi A, Biswal MR (2015) Treatment analysis of paediatric femoral neck fractures: a prospective multicenter theraupetic study in Indian scenario. Int Orthop 39(6):1121-1127. https://doi.org/10.1007/s00264-0152677-y

18. Zhang X, Shao X, Yu Y, Zhang Y, Zhang G, Tian D (2017) Comparison between percutaneous and open reduction for treating paediatric talar neck fractures. Int Orthop. https://doi.org/10.1007/ s00264-017-3631-y

19. Ribeiro da Silva M, Linhares D, Cacho Rodrigues P, Monteiro EL, Santos Carvalho M, Negrão P, Pinto RP, Neves N (2016) Paediatric cervical spine injures. Nineteen years experience of a single centre. Int Orthop 40(6):1111-1116. https://doi.org/10.1007/s00264-0163158-7

20. Kenawey M (2017) Surgical considerations with the operative fixation of unstable paediatric pelvic ring injuries. Int Orthop. https:// doi.org/10.1007/s00264-017-3475-5

21. Nakamura N, Inaba Y, Machida J, Saito T (2015) Rotational openwedge osteotomy improves treatment outcomes for patients older than eight years with Legg-Calve-Perthes disease in the modified lateral pillar B/C border or C group. Int Orthop 39(7):1359-1364. https://doi.org/10.1007/s00264-015-2729-3

22. Kadhim M, Womer RB, Dormans JP (2017) Surgical treatment of pelvic sarcoma in children: outcomes for twenty six patients. Int Orthop. https://doi.org/10.1007/s00264-017-3564-5 